\title{
A heterogeneidade da fala de Professores de Ciências: Analisando modos pensar o
}

\section{conceito de calor}

\author{
The hererogeneity of Science Teachers Speak: Analyzing ways to think the heat concept \\ La hereterogeidad del discurso de los Profesores de Ciencia: Analizando formas de pensar el
}

concepto de calor

Recebido: 30/07/2021 | Revisado: 04/08/2021 | Aceito: 14/08/2021 | Publicado: 16/08/2021

\author{
Kassielly Raimunda Dias da Silva \\ ORCID: https://orcid.org/0000-0002-7964-8226 \\ Universidade Federal Rural de Pernambuco, Brasi \\ E-mail: kassiellydias@hotmail.com \\ Geany de Sousa Lima \\ ORCID: https://orcid.org/0000-0001-7422-7222 \\ Universidade Federal do Vale do São Francisco, Brasil \\ E-mail: geanylima_@hotmail.com \\ Antônio Inácio Diniz Júnior \\ ORCID: https://orcid.org/0000-0002-2207-9376 \\ Universidade Federal Rural de Pernambuco, Brasil \\ E-mail: antonioinaciodj@gmail.com
}

\begin{abstract}
Resumo
Este artigo teve como objetivo analisar os modos de pensar o conceito de calor que emergem na fala de professores de duas escolas públicas de São Raimundo Nonato-PI. Para isso, nos guiamos pela teoria dos perfis conceituais que discute a polissemia de conceitos científicos trabalhados em sala de aula, precisamente o conceito de calor, pois este apresenta grande relevância dentro do ensino de Ciências. Esta pesquisa apresenta caráter qualitativo descritivo, realizada a partir da coleta, análise e mapeamento de falas de dois professores de Ciências do $9^{\circ}$ ano do Ensino Fundamental. A operacionalização dessa pesquisa foi dividida em duas etapas, a primeira a aplicação de um questionário contendo nove questões, a segunda se deu pela observação de três aulas de Ciências, cujo objetivo foi verificar os diferentes modos de falar o conceito de calor quando este é ensinado em sala de aula. A partir de nossos resultados verificamos diferentes modos de pensar o conceito de calor na fala dos professores, a saber: Racionalista, substancialista, realista, empírica e animista. Vale destacar que pudemos observar que os docentes ensinam e articulam a heterogeneidade do conceito de calor em suas aulas, entretanto de forma pouco aprofundada, ou seja, não tendo consciência dos significados que este conceito apresenta. Ressalvamos, a partir das discussões aqui apresentadas, que pretendemos dar continuidade à nossa pesquisa envolvendo o uso dos perfis conceituais na compreensão, planejamento e contextualização do ensino de ciências.
\end{abstract}

Palavras-chave: Perfil conceitual; Calor; Professores.

\begin{abstract}
This article aimed to analyze the ways of thinking about the concept of heat that emerge in the speech of teachers from two public schools in São Raimundo Nonato-PI. For this, we are guided by the theory of conceptual profiles that discusses the polysemy of scientific concepts worked on in the classroom, precisely the concept of heat, as this has great relevance within the teaching of Science. This research has a descriptive qualitative character, carried out from the collection, analysis and mapping of the statements of two Science teachers from the 9th year of Elementary School. The operationalization of this research was divided into two stages, the first was the application of a questionnaire containing nine questions, the second was through observation of three Science classes, whose objective was to verify the different ways of speaking the concept of heat when it is taught in the classroom. Based on our results, we verified different ways of thinking about the concept of heat in the teachers' speech, namely: Rationalist, substantialist, realist, empirical and animist. It is noteworthy that we could observe that the professors teach and articulate the heterogeneity of the concept of heat in their classes, however in a shallow way, that is, they are not aware of the meanings that this concept presents. We emphasize, from the discussions presented here, that we intend to continue our research involving the use of conceptual profiles in the understanding, planning and contextualization of science teaching.
\end{abstract}

Keywords: Conceptual profile; Heat; Teachers. 


\begin{abstract}
Resumen
Este artículo tuvo como objetivo analizar las formas de pensar sobre el concepto de calor que surgen en el discurso de los profesores de dos escuelas públicas de São Raimundo Nonato-PI. Para ello, nos guiamos por la teoría de perfiles conceptuales que discute la polisemia de conceptos científicos trabajados en el aula, precisamente el concepto de calor, ya que éste tiene gran relevancia dentro de la enseñanza de las Ciencias. Esta investigación tiene un carácter cualitativo descriptivo, realizada a partir de la recopilación, análisis y mapeo de los enunciados de dos profesores de Ciencias del $9^{\circ}$ año de Educación Primaria. A operacionalização dessa pesquisa foi dividida em duas etapas, a primeira a aplicação de um questionário contendo nove questões, a segunda se deu pela observação de três aulas de Ciências, cujo objetivo foi verificar os diferentes modos de falar o conceito de calor quando este é ensinado En el aula. Con base en nuestros resultados, verificamos diferentes formas de pensar sobre el concepto de calor en el discurso de los profesores, a saber: racionalista, sustancialista, realista, empírica y animista. Es de destacar que pudimos observar que los profesores enseñan y articulan la heterogeneidad del concepto de calor en sus clases, sin embargo de manera superficial, es decir, desconocen los significados que presenta este concepto. Destacamos, de las discusiones aquí presentadas, que pretendemos continuar nuestra investigación involucrando el uso de perfiles conceptuales en la comprensión, planificación y contextualización de la enseñanza de las ciencias.
\end{abstract}

Palabras clave: Perfil conceptual; Calor; Maestros.

\title{
1. Introdução
}

Neste estudo analisamos o perfil conceitual de calor (Amaral \& Mortimer, 2001), e verificamos como este é pensado por professores de Ciências da rede pública de São Raimundo Nonato- PI, especialmente quando eles mediam o processo de ensino e aprendizagem ao ensinarem Ciências. Além disso, analisamos também ideias prévias desses profissionais a respeito do conceito científico de calor, assim como os seus perfis profissionais.

Para este estudo, nos guiamos pela a teoria dos perfis conceituais (Mortimer, 1995, Mortimer, \& El-Hani, 2014) que permite discutir os diferentes compromissos epistemológicos, ontológicos e axiológicos que um perfil conceitual pode apresentar, defendendo a ideia da polissemia dos conceitos, isto é, que um com conceito abrange múltiplos significados. Estas diferentes ideias, dentro da teoria podem ser categorizadas em zonas, que são modos de pensar e cuja empregabilidade se resulta em estruturar visões e percepções a respeito de um dado conceito. Cada modo de pensar corresponde a uma diferente visão de mundo diretamente relacionada com diferentes maneiras de pensar e distintos modos de falar um dado conceito (Amaral; Mortimer, 2005).

Destarte, a teoria dos perfis conceituais ajuda a entender essa pluralidade dos conceitos e a utilização destes de forma consciente, ao passo que há o assentimento de que existem dificuldades em promover o ensino eficiente e igualitário dos conhecimentos científicos no ensino de ciências (Araújo \& Mortimer, 2014). Logo, compreende-se que existe a necessidade de investir na difusão do conhecimento científico, explorando as contribuições da teoria dos perfis conceituais para o ensino de Ciências.

Assim sendo, na sala de aula, o discurso plural pode estar associada aos diferentes significados e sentidos que os alunos atribuem a um conceito, quando o professor ensina os conteúdos escolares (Sabino \& Amaral, 2018). Ainda de acorda com as autoras, durante esse processo o conhecimento científico pode ser confrontado com maneiras de pensar distintas à medida que o professor contextualiza o conteúdo e promove interações discursivas, mobilizando em sua fala diversas ideias que corroboram com processo de conceituação vivenciado pelos alunos em sala de aula de Ciências, pois no processo de construção de significados a contextualização e interações professor- aluno exercem papel fundamental na organização de formas de falar que se articulam entre os diferentes modos de pensar sobre um determinado conceito científico quando se discutem os conteúdos estudados (Diniz \& Amaral, 2019).

Nesse sentido, Mortimer e Amaral (1998) consideram que muitos estudantes têm dificuldades em compreender conceitos comuns, que são utilizados no cotidiano, pois o professor em muitos casos não reflete acerca de como seus discentes aprendem, isto é, ensinam sem levar em conta os conhecimentos prévios desses estudantes, sem que o educando consiga 
perceber claramente os limites e contextos de aplicação. Por isso, Santos e Carbó (2004) enfatizam essa problemática, ao afirmarem que "os estudantes, em geral, não são conscientizados ou sensibilizados para essas mudanças semânticas e, assim, continuam a atribuir a esses termos os vagos significados metafóricos previamente absorvidos” (p. 2).

Considerando a heterogeneidade apresentada nas salas de aulas (Diniz, Silva, \& Amaral, 2015) discutem que os conceitos científicos e cotidianos vem passando por modificações no modo de aprender e ensinar, e defendem que os professores se debrucem cada vez mais em buscar melhorias para aprendizagem em sala de aula, e entendam que suas ações estabelecem importante pontes entre o conhecimento e os estudantes, pois o ato de ensinar institui relações entre educando e mundo científico e social.

Assim, em meio ao discurso do processo de conceituação, é necessário e relevante se pensar sobre como esses profissionais pensam e falam determinados conceitos, uma vez que, estes são os principais mediadores do processo de ensino e aprendizagem. Por conseguinte, neste estudo buscamos contribuir para que professores tenham consciência da diversidade de significados que os conceitos trabalhados em sala de aula exibem, ajudando-os a representar cada significado em seu contexto específico, ressalvando a relevância em trabalhar os múltiplos significados de um dado conceito e sua funcionalidade quando aplicados em empregos específicos.

Deste modo, temos o como objetivo, analisar os modos de pensar o conceito de calor que emergem na fala de professores de duas escolas públicas de São Raimundo Nonato - PI.

\section{A Teoria dos perfis conceituais}

A teoria dos perfis conceituais, proposta por (Mortimer \& El-Hani, 2014), prevê a pluralidade que um único conceito possui, assinalando muitos significados que podem coexistir em um determinado conceito. Ao pensar a teoria dos perfis conceituais (Mortimer, 1995; Mortimer \& El-hani, 2014), percebemos que esta traz grandes contribuições para o ensino de Ciências, pois sua proposta ajuda organizar o desenvolvimento de conceitos dentro da sala de aula, identificando também lacunas nesse sistema oriundas da resistência a evolução de conceitos mais avançados, uma vez que um mesmo indivíduo pode expressar diferentes sentidos de um mesmo conceito e aplicá-lo a contextos diversos.

Reconhecendo que os conceitos costumam ser polissêmicos, tanto na Ciência quanto na linguagem cotidiana (Freire, Talanquer, \& Amaral, 2019), na teoria dos perfis conceituais, são considerados pressupostos da perspectiva sociocultural, a partir da qual a aprendizagem em Ciências é entendida como a aprendizagem da linguagem social da ciência escolar (Mortimer \& Scott, 2002). Outros pressupostos teóricos estão na base dessa teoria, tais como: o construtivismo contextual (Cobern, 1996),

o método genético ou de desenvolvimento para a constituição do pensamento conceitual (Vigostki, 1978, 1981, 1987) e as perspectivas da linguagem como vivência e a teoria de enunciação (Bakhtin, 1986). Com isso, é constituído um modelo teórico para análise de modos de pensar, formas de falar e do processo de conceituação em situações de ensino e aprendizagem de Ciências (Mortimer \& El-Hani, 2014).

Dessa forma, a teoria em questão valoriza os diferentes modos de pensar os conceitos, contextos e linguagens científicas a partir da construção de perfis conceituais, inserindo novas possibilidades de desenvolver a educação científica de forma construtiva, não permitindo que uma única forma de pensamento se sobressaia sobre outras (Amaral \& Mortimer, 2006). Para Araújo (2014, p. 01), "O perfil conceitual é uma noção relacionada ao ensino e à aprendizagem de conceitos científicos e fundamenta-se no princípio de que um conceito pode abranger uma diversidade de significados, os quais podem ser aplicados de acordo com o contexto. Assim sendo, o indivíduo pode desenvolver diferentes modos de ver e conceituar o mundo, a partir da própria experiência".

Assim, essa teoria concebe as diferentes maneiras de representar e significar o mundo, elucidando que um determinado conceito pode ser empregado em diferentes situações, e tem valor pragmático em contextos apropriados, 
apresentando sentidos diferentes, mas sendo que nenhuma concepção predomina em relação à outra, pois se compreende que cada ideia tem sua importância e uma empregabilidade a contextos distintos (Mortimer, 1996).

É importante salientar o valor que ambas as concepções oferecem, segundo Silva e Amaral (2013) o uso de determinados compreensões podem se limitar à determinados contextos, ou seja, que algumas concepções têm sua expressão limitada a dadas abordagens, validando a presença de outras compreensões, nesse aspecto exigindo a abrangência e utilização da percepção do perfil conceitual, porquanto cada significado expressado está ligado a compromissos distintos, defendendo a ideia da polissemia dos conceitos (Simões, 2016).

Deste modo, compreendemos que cada indivíduo possui distintos olhares sobre a realidade a sua volta, tendo diferentes formas de pensar uma situação ou conceito, de acordo com cada contexto, podendo entrelaçar conhecimentos preexistentes com novas formas de pensar edificadas durante a vida. Essas representações de diferentes olhares sobre um conceito permitem agrupá-las quanto a sua caracterização em zonas do perfil conceitual, que são modelos utilizados para representar expressões a partir de pontos de vista (Diniz et al, 2015).

Ressalvamos assim, a relevância de compreender a polissemia que um conceito dispõe, pois essa faceta reconhece pontes quanto ao desenvolvimento do processo de ensino e aprendizagem de conceitos científicos, possibilitando uma melhor compreensão evolutiva dessas concepções (Araújo, 2014).

\section{O Perfil conceitual e a sala de aula}

Segundo Sepúlveda (2008) o ensino de Ciências ao longo dos anos vem passando por mudanças que exigem mais a participação do alunado nas discussões em sala de aula, e trazer o cotidiano dos mesmos para este ambiente é importante para a compreensão da concepção de que a ciência abandonou a ideia de lei absoluta da verdade, incapaz de mudanças.

$\mathrm{O}$ perfil conceitual permite uma mediação no processo de ensino e aprendizagem, abrindo espaços para novas discussões, permitindo e ampliando a inserção de novos contextos para a sala de aula. Pois, segundo Araújo (2014, p. 8) "as pesquisas sobre perfis conceituais têm se mostrado úteis para a educação em ciências, pois auxiliam na proposição de um processo de ensino voltado para a valorização das diversas concepções que podem ser atribuídas a um conceito".

Possibilitando aos estudantes, a aprendizagem de conhecimentos científicos, sem a pressão de ter que abandonar sua bagagem cotidiana de conhecimento.

O espaço de interação em sala de aula necessita de um suporte que lhe permita abranger e incluir novas formas de pensamento, novas formas de apoio para o desenvolvimento e potencialização da aprendizagem, auxiliando de forma produtiva a construção de novas formas de ver e interpretar conceitos, preservando também conhecimentos prévios. Diante disso, o contexto do ensino de Ciências é cada vez mais preciso refletir a realidade da pluralidade conceitual por meio da teoria do perfil conceitual, na qual considera as diferentes formas de ver conceitos e a realidade, como forma de agregar conhecimentos (Coutinho, Mortimer, \& El-Hani, 2007).

De acordo com Castro e Ferreira (2015) é importante discutir as concepções dos estudantes também oriundas do senso comum, ou seja, conhecimentos edificados durante a vivência cotidiana, pois pode ajudar na conscientização dos próprios indivíduos, uma que pode funcionar como suporte na aprendizagem de novos conceitos, além de alertar para possíveis resistências deles no processo de ensino e aprendizagem. Ressaltamos também, a importância da conscientização do professor a respeito do perfil conceitual (Mortimer, 1995), pois ele representa uma importante ponte no processo de ensino e aprendizagem, sendo um sujeito imprescindível, capaz de ampliar os horizontes científicos de seus estudantes.

Segundo Schnetzler (1992) cada professor se orienta a partir de uma dada maneira de lidar com a sala de aula, própria de cada profissional, isto é, a forma como os conteúdos são passados por ele esta diretamente ligado a forma com seus alunos aprendem. Para Capecchi e Carvalho (2000) os estudantes adquirem as formas de falar própria de cada professor, ou seja, o 
professor com seu modo de ensinar, manifesta concepções de educação, de linguagens e conhecimento (Schnetzler, 1992). Por isso, compreendemos que a conscientização dos múltiplos significados que um conceito exibe desses profissionais é imprescindível para a forma como o alunado irá aprender.

É importância salientar que o papel do professor na aprendizagem é nítida, pois ele se torna um elo entre conhecimento e seus estudantes, capaz de edificar e ampliar o arcabouço de concepções, ajudando-os a se tornarem sujeitos ativos e críticos. Diniz et al, (2015, p. 56) enfatizam o valor e a representação social do docente, pois este atua diretamente no âmbito de formação e desenvolvimento de opiniões, responsável por "construir sentidos e inclusões dentro da sala de aula".

\section{Perfil conceitual de calor}

O conceito de calor é um dos mais antigos que se tem notícia, desde tempos remotos que se emprega a esse conceito diferentes realidades e serventias. O fogo, conhecido pelo homem desde o Homem de Neandertal, a 300.000 anos atrás, já era considerado como importante fonte transmissora de calor (Araújo, 2014, p. 19).

Ao longo do tempo, surgiram diversas formas de representar o conceito de calor (Araújo, 2014), tornando o uso deste cada vez mais comum e indo além da empregabilidade cotidiana, alcançando também âmbitos escolares e acadêmicos, viabilizando uma averiguação mais aprofundada a respeito da sua funcionalidade.

O perfil conceitual de calor proposto por Amaral e Mortimer (2001) ratifica as muitas serventias oferecidas por este conceito, apontando sua grande importância, já que seu uso é nitidamente relevante e frequente em diferentes esferas, pois seus significados norteiam cotidianamente a vida das pessoas. "Dentre os conceitos tidos como abstratos, o de calor é de grande relevância, uma vez que tem dimensão interdisciplinar, sendo visto nas ciências exatas, biológicas e engenharias, além de estar presente no dia a dia dos alunos" (Castro \& Ferreira, 2015, p. 26). Para Freire et al (2019), "O reconhecimento e a reflexão sobre as diferentes maneiras como o calor é conceituado em vários contextos nos ajudam a desenvolver uma compreensão mais profunda deste conceito científico.

Diante disso, o perfil conceitual de calor apresenta cinco modos de pensar, a saber: realista, empírica, substancialista, animista e racionalista. Cada uma delas abrange suas características específicas, que permitem identificá-las na fala de diferentes sujeitos (Amaral \& Mortimer, 2001).

Segundo Araújo (2014), na zona realista, calor está ligado a ideias do cotidiano, deste modo relacionado a sensações térmicas de quente e frio. Negando assim, a existência de um equilíbrio térmico, uma vez que estabelece a temperatura como propriedade do corpo.

A zona empírica trata calor a partir da medida deste no corpo, isto é, calor é associado a elevadas temperaturas. Contudo, diferente de sensações térmicas, a temperatura nesta zona, é usada empiricamente como medida de calor.

Apresentado como uma substancia, capaz de fluir entre corpos. Calor na zona substancialista é pertencente ao um corpo e penetra em outros, no entanto inerte.

Atribuindo vida a calor, na zona animista calor é pensado com substancia viva, capaz de penetrar corpos.

Zona racionalista, reuni compromissos que melhor representam a visão científica, nessa zona calor é apresentado a partir do contato direto entre corpos diferentes e da energia em trânsito entre esses sistemas, isto é, energia em movimento, na qual temos a representação de calor quanto ao movimento cinético, pois nessa o calor apresenta caráter de movimento e de quantificação matemática.

\section{Metodologia}

Esta pesquisa possui estrutura qualitativa descritiva, apresentando, caráter exploratório e subjetivo. Tendo em vista, que o ser humano em suas ações cotidianas interpreta a realidade a sua volta, a pesquisa qualitativa prima pela interação e 
interpretação do homem como ser ativo a sua realidade (Guerra, 2014). Destarte, investigar é uma prática que fundamenta o entendimento, compreendendo que ações são melhores averiguadas quando analisadas ante o próprio cenário, elucidando a pesquisa qualitativa.

A pesquisa foi desenvolvida em duas escolas públicas do município de São Raimundo Nonato-PI, uma de rede estadual e a outra municipal, ambas de Ensino Fundamental, anos iniciais e finais. Os sujeitos participantes foram dois professores de Ciências que lecionam nas turmas de $9^{\circ}$ ano das respectivas escolas. Aqui trataremos o professor da escola municipal como, Professor A, por ter sido o primeiro que se realizou a coleta de dados. Por conseguinte, o professor da escola estadual, será tratado de professor B. A escolha dos sujeitos da pesquisa ocorreu de acordo com a disponibilidade desses profissionais em participar da pesquisa.

\subsection{Etapas da pesquisa}

Para realização do desenvolvimento da pesquisa, dividimos a coleta de dados em duas etapas, sendo a primeira a aplicação de um questionário contendo nove questões, levantando o perfil profissional dos sujeitos, assim como concepções prévias destes ao tratarem do conceito de calar. A segunda etapa se deu pela observação de três aulas de Ciências do $9^{\circ}$ ano, com o intuito de entender como é trabalhado o conceito de calor para que pudéssemos identificar quais zonas do perfil conceitual de calor (Amaral \& Mortimer, 2001; Araújo, 2014) se inserem as falas dos sujeitos da pesquisa.

Ressaltamos que o professor A ministrou uma aula das três aulas observadas, e o professor B, duas aulas, cada aula teve a duração de 50 minutos. Destacamos ainda, que a diferença no número de aula se deu pela disponibilidade de cada profissional em ministrar as aulas, pois a priori seria o mesmo número de aulas para cada docente. Mas tal alteração não fragilizou os resultados.

Na realização da pesquisa foram utilizados equipamentos de registro de vídeo, durante a observação em sala de aula, foram usadas câmeras digitais e aparelhos smartphones. Os dados obtidos dos registros em vídeo foram transcritos para a análise.

A seguir, trataremos de forma detalhada as etapas da pesquisa.

Primeira etapa - Foi aplicado um questionário com nove questões, no qual continha perguntas sobre o perfil profissional dos sujeitos da pesquisa e questões visam entendem conhecimentos prévios dos sujeitos a respeito do conceito de calor e da teoria do perfil conceitual.

Segunda etapa - Foi realizada a observação de três aulas de Ciências do $9^{\circ}$ ano do Ensino Fundamental para identificar as principais ideias que emergem na fala dos professores investigados.

\section{Análise dos dados}

Para análise de dados desta pesquisa, nos conduzimos pelos estudos de Amaral e Mortimer (2001) e Araújo (2014), em que discutiram os diferentes modos de pensar e falar o conceito de calor, denominados de zonas.

\section{Análise do questionário}

Por meio da aplicação do questionário, foi possível extrair informações que corroboraram para traçar o perfil de cada docente, contribuindo para qualificar os resultados obtidos durante a análise em sala de aula. Dessa forma, foi possível identificar dados, a saber: Área de formação, anos de magistério, Tempo que leciona Ciências, acesso a pesquisas e atualizações na área do ensino de Ciências. 


\section{Análise da observação em sala de aula}

Após serem observadas, filmadas e transcritas, as aulas de ciências foram analisadas, verificando assim, quais zonas predominam na fala dos dois docentes. Assim, toda análise foi realizada utilizando os compromissos ontológicos e epistemológicos das zonas do perfil conceitual de calor, obedecendo as principais características elencadas por Araújo (2014), conforme ilustradas no Quadro 1.

Quadro 1. Zonas do perfil conceitual de calor.

\begin{tabular}{|c|c|}
\hline Zona & Características \\
\hline Realista & Calor é associado a sensações térmicas. \\
\hline Animista & Calor é atribuído como forma de vida. \\
\hline Substancialista & Calor é entendido como uma substância inerte. \\
\hline Empírica & Calor é relacionado a elevação de temperatura. \\
\hline Racionalista & $\begin{array}{r}\text { Calor é apresentado como uma relação matemática e como dissipação de energia } \\
\text { associada ao movimento molecular. }\end{array}$ \\
\hline
\end{tabular}

Fonte: Araújo (2014).

\section{Resultados e Discussão}

Para análise dos dados e identificação das zonas do perfil conceitual, nos guiamos pelos estudos de Amaral e Mortimer (2001) e Araújo (2014) sobre o conceito científico de calor. Deste modo, trataremos nesta seção da aplicação do questionário e das ideias dos professores A e B sobre calor ao ensinarem Ciências no $9^{\circ}$ ano do Ensino Fundamental. Logo mais, apresentamos os resultados alcançados acerca do perfil profissional dos sujeitos da pesquisa.

\subsection{Aplicação do questionário}

A seguir, no Quadro 2, apresentamos os resultados alcançados acerca do perfil profissional dos sujeitos da pesquisa.

Quadro 2. Resultados do questionário acerca do perfil profissional dos sujeitos da pesquisa.

\begin{tabular}{|c|c|c|}
\hline PERGUNTAS & PROFESSOR A & PROFESSOR B \\
\hline $\begin{array}{l}1^{\text {a }} \text {-Qual sua área de formação? O } \\
\text { senhor(a) sempre atuou nessa área? }\end{array}$ & $\begin{array}{l}\text { Licenciatura em ciências biológicas. } \\
\text { Normalmente atuo nesta área e em } \\
\text { outras como: história, geografia, arte, } \\
\text { ensino religioso. }\end{array}$ & Ciências biológicas. Não. \\
\hline $\begin{array}{l}2^{a} \text {-A quanto tempo o senhor(a) atua em } \\
\text { sala de aula? }\end{array}$ & 14 anos( na $8^{a}$ serie 3 anos). & 9 anos. \\
\hline $\begin{array}{l}3^{\mathrm{a}} \text {-Na sua concepção de professor de } \\
\text { Ciências, o que é calor? }\end{array}$ & $\begin{array}{l}\text { É uma energia(força) que faz com } \\
\text { que corpos(matéria) se movimente ou } \\
\text { transforme-se através da } \\
\text { transferência de temperatura entre os } \\
\text { corpos.(Seja para mudar de estado } \\
\text { para outra, para se deslocar, gerar } \\
\text { vida) }\end{array}$ & $\begin{array}{l}\text { É transferência de energia que é } \\
\text { importante para os seres vivos. }\end{array}$ \\
\hline $\begin{array}{l}4^{\text {a }} \text {-Calor, é um conceito importante para } \\
\text { se trabalhar nas aulas de ciências? } \\
\text { Porque? }\end{array}$ & $\begin{array}{l}\text { Sim. Por que é uma energia que move } \\
\text { ou transforma corpos do universo, e } \\
\text { este são a base de estudo. }\end{array}$ & $\begin{array}{l}\text { Sim, pois é transferência de } \\
\text { energia que é importante para os } \\
\text { seres vivos. }\end{array}$ \\
\hline $\begin{array}{l}5^{\text {a }} \text {-Como o(a) senhor(a) ensina o } \\
\text { conceito de calor em sala de aula? }\end{array}$ & $\begin{array}{l}\text { Que é uma energia térmica que } \\
\text { através do aumento ou diminuição da } \\
\text { temperatura do corpo, pode mudar o } \\
\text { estado em que a matéria se encontra. }\end{array}$ & $\begin{array}{l}\text { Através de diálogo e com exemplo } \\
\text { do cotidiano dos alunos. }\end{array}$ \\
\hline $\begin{array}{l}\text { 6- Para o(a) senhor(a) qual a relação } \\
\text { entre: }\end{array}$ & a- Temperatura é uma grandeza & a- Calor é a energia térmica \\
\hline
\end{tabular}




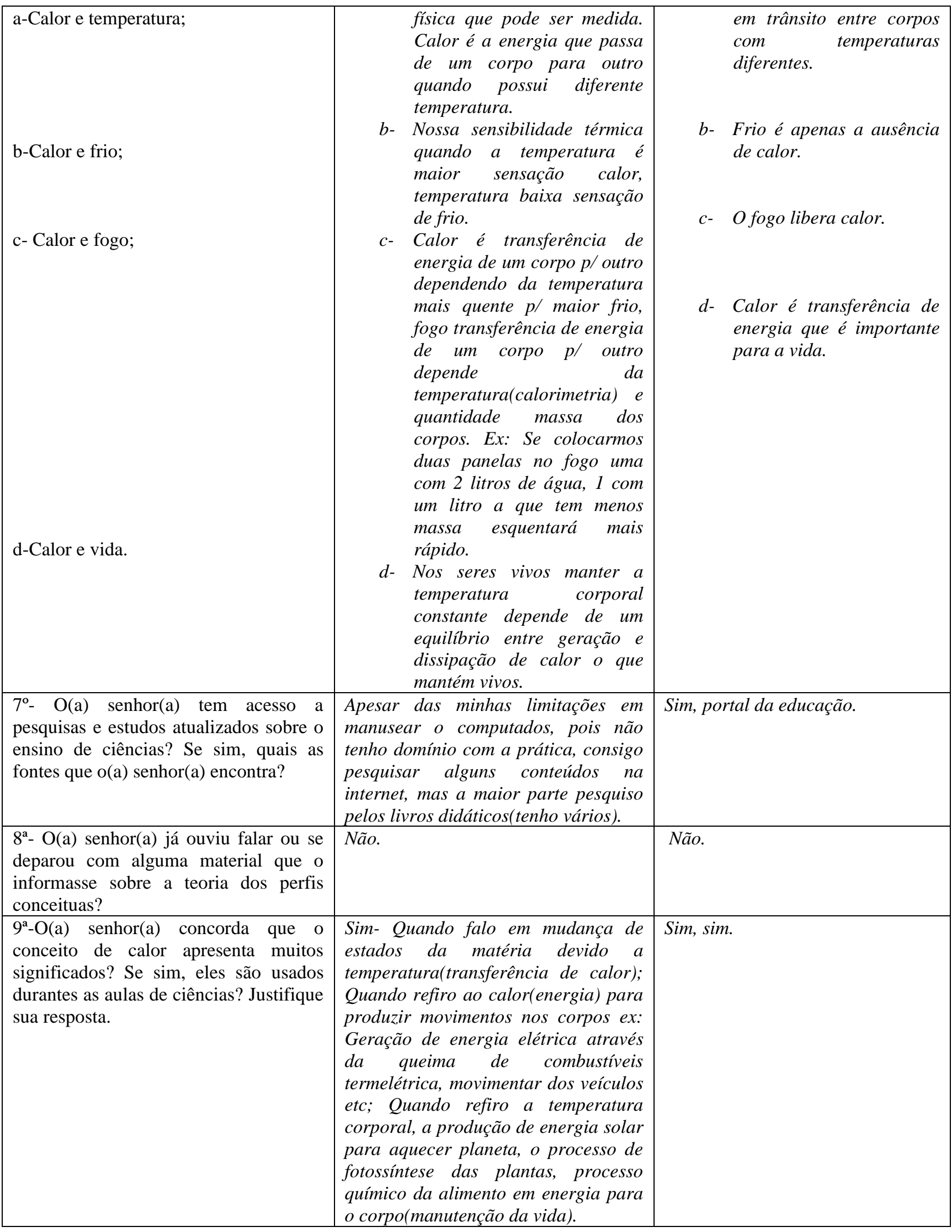

Fonte: Autores (2021). 
Conforme podemos verificar no Quadro 2, os professores participantes da pesquisa, são licenciados, ambos possuindo graduação em Ciências Biológicas. O professor A apresenta quatorze anos de atuação em sala de aula. O professor B, possui menos tempo de atuação em sala de aula, nove anos.

Em resposta as perguntas três e quatro no Quadro 2, o professor A, demonstrou ideias ligadas à zona animista e empírica, apontando calor como energia em movimento e podendo gerar vida, bem como as ideias empíricas relacionadas entre a diferença de temperatura entre corpos, declarando ainda ser importante trabalhar o conceito de calor em sala de aula. $\mathrm{O}$ professor B aponta a concepção de calor ligada a zona racionalista (calor, como energia em trânsito), afirmando que este conceito deve ser trabalhado durante as aulas, pois segundo professor B, calor é uma energia importante para os seres vivos.

Nas perguntas cinco e seis, Quadro 2, os docentes foram indagados quanto a forma que ensinam o conceito de calor e a demonstrar suas concepções a respeito do mesmo, na qual foram direcionados a fazer relações de calor com vida, temperatura, frio e fogo. Assim, de acordo com a fala do professor A, este demostrou de forma mais concreta e científica sua forma de trabalhar calor em sala de aula, pois o professor B, apenas apontou que trabalha o conceito a partir de diálogo e com exemplos cotidianos.

Conforme podemos verificar, o professor A ao fazer alusões de calor com temperatura, trouxe calor como energia em movimento, característica oriunda da zona racionalista. Da mesma forma, o professor B, ratifica a exemplificação do professor A, abordando calor ao "movimento cinético de partículas microscópicas" entre corpos. (Araújo, 2014. p. 44). Em relação a relação com calor e frio, professor A, atribui a calor e frio uma forma de sensibilidade térmica, cujo principio é a alta e baixa de temperatura, representando compromissos da zona empírica. Enquanto, o professor B, atribui ao frio somente a ausência de calor.

Seguindo na questão seis, Quadro 2, o professor A ao pautar calor e fogo, relaciona calor a de transferência de energia, proporcional ao movimento molecular, evidenciando a presença da zona racionalista (Araújo, 2014). Assim também, o professor B, ao fazer menção de calor e fogo, trás ideia referente a transferência de energia, adequada a zona racionalista. Finalizando a questão seis, ao serem indagados a relacionar calor e vida, ambos os docentes trataram calor como dissipação de energia, compartilhando caracteres da zona racionalista.

Referindo-se as questões sete, oito e nove, no Quadro 2, os dois professores foram questionados a respeito do acesso a estudos e pesquisas atualizadas referentes ao ensino de ciências, se já teriam dito acesso a estudos relacionados a teoria dos perfis conceituais e por fim, foram investigados com relação ao conteúdo que foi apresentado a eles durante a pesquisa, se a partir desse primeiro contado com a teoria em estudo, eles concordavam que calor é um conceito polissêmico, e se seus múltiplos significados eram empregados durante suas aulas. Respondendo a esses questionamentos, ambos os profissionais declaram nunca terem sido informados a respeito da teoria dos perfis conceituais e que tem acesso a internet para pesquisas sobre o ensino de ciências. Os dois também reconhecem o pluralismo do conceito de calor e afirmam usá-los durantes as aulas, no entanto somente o professor A, detalhou como trabalha este conceito e seus muitos significados em sala de aula.

A seguir ilustramos partes de falas dos docentes extraídos das três aulas de Ciências observadas durante a pesquisa, para esta ilustração, seguiremos a ordem alfabética.

\subsection{Observações das aulas do professor A}

Nas aulas do professor A, identificamos a presença das cinco zonas do perfil conceitual calor, a saber: Realista, empírica, substancialista, animista e racionalista (Amaral \& Mortimer, 2001), que serão mais exploradas, a seguir, no Quadro 3. 
Quadro 3. Extratos da fala do professor A.

\begin{tabular}{|c|c|}
\hline EXEMPLOS DE FALAS & IDENTIFICAÇÃO DAS ZONAS \\
\hline $\begin{array}{l}\text { Quando ele for alimentado, olha ai: Quando pularam no mar, } \\
\text { Kelvin e Haroldo sentiram frio porque? Seus corpos perderam } \\
\text { calor para a água do mar, ou seja, quando eles pularam quem } \\
\text { estava, qual era corpo que estava mais quente, os corpos do } \\
\text { Haroldo mais do Kelvin está mais quente do que a água do } \\
\text { mar? quem está mais quente, a água do mar ou os corpos do } \\
\text { dos do Haroldo ai mais do, quem está mais quente? }\end{array}$ & REALISTA \\
\hline $\begin{array}{c}\text { Começar a sentir náuseas, dai desmaia, vai perder calor o seu } \\
\text { corpo, você pode vir a morrer sim, do mesmo jeito se aumenta } \\
\text { pra } 38^{\circ} \text {, pra } 37,5 \text { você á está com febre, quando mais aumenta, } \\
\text { se chegar a } 40^{\circ} \text {, a suas células não suporta esse, essa é... } \\
\text { temperatura e elas vão se degenerar, se chegar a } 42^{\circ} \text {, os } \\
\text { termômetros geralmente marcam de } 35 \text { até } 30,42^{\circ} \text {, mas e a, e a } \\
\text { temperatura do corpo chegar a } 32^{\circ} \text { praticamente seu corpo tá } \\
\text { fervendo }\end{array}$ & EMPÍRICA \\
\hline $\begin{array}{c}\text {. Na vibração das partículas, ela ficam mais rápido e vai } \\
\text { passando é... por sua vez elas entram em contado com as } \\
\text { moléculas vizinhas da partícula da colher e ela vai subindo até } \\
\text { chegar a extremidade da colher, esse processo ocorre } \\
\text { sucessivamente e leva a propagação do calor ao longo da } \\
\text { colher, então ela vai passando, é.. as partículas vão se } \\
\text { agitando porque vão recendo calor e vai subindo até chegar a } \\
\text { extremidade da colher }\end{array}$ & SUBSTANCIALISTA \\
\hline $\begin{array}{c}\text { O que for matéria, essa matéria pra ela seja transformada, } \\
\text { movimentada precisa da ener? Energia, que é uma força que } \\
\text { aplicada a um determinado corpo vai fazer com que esse corpo } \\
\text { se transforme, mude de posição, de deslocamento, nós já vimos } \\
\text { sobre isso também, né isso? }\end{array}$ & ANIMISTA \\
\hline $\begin{array}{l}\text { Calor, nós falamos muito nessa energia térmica chamada } \\
\text { calor, olha ai calor: energia térmica em trânsito devido a } \\
\text { diferença de temperatura dos corpos, energia térmica em } \\
\text { trânsito devido a diferença de temperatura dos corpos, olha ai; } \\
\text { diferença de temperatura dos corpos em trânsito porque está } \\
\text { em movimento, ou seja, varie um pouco, mude de movimento } \\
\text { reto, um movimento que gere, mude de movimento pra outro, } \\
\text { ou ele seja transformado ou passado de um estado pra outro } \\
\text { ele precisa dessa energia térmica, o calor, por isso que isso diz } \\
\text { que está em movi? movimento e pra que aja essa energia } \\
\text { térmica, pra que aja essa energia térmica que vai mudar a é... } \\
\text { um corpo de um estado pra outro devido a diferença de } \\
\text { temperatura 'é preciso que o corpo, essa energia sempre } \\
\text { sempre passe de o corpo que tem maior temperatura pra o de } \\
\text { menor temperatura. }\end{array}$ & RACIONALISTA \\
\hline
\end{tabular}

Fonte: Autores (2021).

Conforme podemos observar no Quadro 3, durante a aula do professor A, notamos a emergência de diferentes modos de pensar. Dentre os quais, destacamos que algumas foram mais frequentes na fala do professor, quais sejam, empírica, racionalista e substancialista, por seguinte, temos a zona realista, e por fim e com menor frequência a zona animista.

Assim, na primeira fala do Quadro 3, percebemos que o professor A aponta em sua fala compromissos característicos da zona realista ao abordar calor a partir de sensações térmicas, noção de quentura, nessa zona os objetos tendem a transmitir calor, frio e quente (Araújo, 2014).

Na segunda fala, verificamos que o professor A deslocou-se dentro de compromissos da zona empírica, cuja apreciação corresponde à ideia de calor como elevação de temperatura, a temperatura por sua vez é utilizada como medida de 
calor nos corpos. Na terceira fala, o professor A faz menção ao movimento de partículas propagando-se dentro de um corpo, uma substancia inerte, propriedades da zona substancialista, que compreende calor como fluído capaz de penetrar corpos. Na quarta fala, temos a presença na zona animista, zona cuja aparição nas falas deste docente foi a menos registrada. Nessa, o professor aludi calor dentro de uma perspectiva de descolamento motivado por uma força, isto é, atribui vida ao calor, pela qual é capaz de deslocar-se por objetivos que desejam receber calor, assim como perdê-lo.

Ao contextualizar calor como movimento de energia a partir de quantificações físicas de partículas que acompanha os movimentos dos corpos, o professor trás ideias de calor como energia em trânsito, isto é, "energia relacionada ao movimento de cinético de partículas" (Araújo, 2014, p. 44), relacionado ao movimento matemática dessa energia, tratando em sua fala calor dentro da zona racionalista.

Assim sendo, conforme os dados apresentados no Quadro 3, verificamos que o professor, mesmo de forma inconsciente, notamos que as menções feitas por ele, tratam preferencialmente calor como energia em movimento, ou seja, calor como ideia de zona racionalista, usando para isso exemplos próximos do conhecimento científico, pois é nessa zona que estão reunidos compromissos epistemológicos próximos dos aceitos pela ciência escolar. De acordo com Diniz Júnior et al (2015), esse fato é recorrente, pois muitos docentes apresentam suas ideias restritas ao conteúdo do livro didático, evidenciando assim concepções de cunho científico, esse fato é positivo, pois evita que a aprendizagem dos estudantes fique alinhada a visões alternativas, mas os compromissos ontológicos e axiológicos não imprescindíveis no processo de conceituação, pois os ajuda a compreender a pluralidade do discurso em sala de aula.

\subsection{Observações das aulas do professor B}

Nas duas aulas, ministradas pelo professor B, identificamos a presença das cinco zonas do perfil conceitual de calor, racionalista, empírica, substancialista, animista e racionalista, conforme ilustramos no Quadro 4, a seguir.

Quadro 4: extratos da fala do professor B.

\begin{tabular}{|c|c|}
\hline EXEMPLOS DAS FALA & IDENTIFICAÇÃO DE ZONAS \\
\hline $\begin{array}{l}\text { Ai nós temos aqui, vamos fazer um esqueminha, aqui eu } \\
\text { tenho digamos, o corpo A, colocar aqui que está quente, } \\
\text { certo? E aqui ao lado um corpo B, que está frio. Eles } \\
\text { representam dois sistemas, onde eu tenho um que é } \\
\text { quente e outro é frio. }\end{array}$ & REALISTA \\
\hline $\begin{array}{l}\text { É diferente, ai tem algumas, tem aparelhos pra (sic), a } \\
\text { temperatura ó ela, ela vai medir com exatidão a } \\
\text { quantidade ai de, qual o grau de agitação que tem ai em } \\
\text { um sistema, qual é a quantidade, por exemplo, qual o } \\
\text { calor que você, que vai tá naquele momento, por } \\
\text { exemplo, um exemplo de aparelho de medir,é o que? } \\
\text { Quem lembra? }\end{array}$ & EMPÍRICA \\
\hline $\begin{array}{l}\text { Ao grau de agitação, Ao somatório dessas energias } \\
\text { cinéticas, do movimento das partículas vai dá-se o nome } \\
\text { de energia térmica, certo? }\end{array}$ & SUBSTANCIALISTA \\
\hline $\begin{array}{l}\text { Eu quero que vocês observem que na escala Celsius, a } \\
\text { água ela entra em fusão quando ela está congelada em } 0^{\circ} \\
\text { né isso? E não acontece na escala Celsius, na escala } \\
\text { celsius qual é o ponto? }\end{array}$ & ANIMISTA \\
\hline $\begin{array}{l}\text { De energia térmica, calor é transferência de energia } \\
\text { térmica de um sistema, de um sistema para outro, certo? }\end{array}$ & RACIONALISTA \\
\hline
\end{tabular}

Fonte: Autores (2021). 
Conforme podemos conferir no Quadro 4, durante as duas aulas do professor B, pudemos averiguar que a zona que povoa com maior frequência suas falas, é a zona empírica, na qual identificamos grande quantidade de extratos que exprimem características referentes a essa zona, nesta zona calor é compreendido como elevação de temperatura, estando relacionado a medida de calor do corpo (Araújo, 2014).

De acordo com o Quadro 4, em sua primeira fala, o professor B faz alusões de calor a partir de noções cotidianas de quente e frio, reconhecendo a presença de sensações térmicas, enfatizando em sua fala compromissos da zona realista. Na fala dois, o professor trata calor a partir de temperatura como medida de calor, representando em sua fala a zona empírica, Segundo Amaral e Mortimer (2001), o modo de pensar empírico é um compromisso ontológico muito recorrente no discurso de estudantes e professores, e é um conhecimento influenciado por eventos da História da Química, na qual as misturas de substâncias eram observadas a partir da medição da temperatura.

$\mathrm{Na}$ terceira fala, Quadro 4, percebemos a presença da zona substancialista, pois ao falar de energia como substância imóvel, pertencente a um corpo com a capacidade de penetrar em outro corpo, ele trata calor como um fluido inerte. De acordo com Amaral e Mortimer (2001), o modo de pensar de calor como substância foi fortemente influenciado pela perspectiva aristotélica, em que nesse período, o calor tinha a capacidade de entrar e sair dos corpos. Já, a quarta fala deste docente, verificamos compromissos da zona animista, zona cujos os atributos de calor lhe conferem vida, isto é, calor é capaz de dar vida a objetos, assim com expressado pelo professor B nesta fala. Esse modo de pensar, conforme Amaral e Mortimer (2001) é um compromisso ontológico que foi bastante evidente no período da alquimia, quando o calor era tratado como uma entidade que tinha vida. Na última fala do Quadro 4, o docente apresenta a ideia de calor como movimento de energia entre corpos, uma que faz alusões aos estados físicos, ao movimento cinético de partículas, isto é, calor foi representado como energia presente em processos, evidenciando assim, a zona racionalista que trás calor como energia em trânsito.

A partir da observação das aulas de Ciências, constatamos que os professores ensinam e articulam a heterogeneidade do conceito de calor em suas aulas, entretanto de forma pouco aprofundada, ou seja, não tendo consciência dos significados que este conceito apresenta, pois em variados momentos das aulas as ideias conseguiram explorar de compromissos epistemológicos, ontológicos e axiológicos que o perfil conceitual possui.

Averiguamos também que ambos os professores trouxeram em suas falas compromissos de todas as zonas do perfil conceitual de calor (Amaral \& Mortimer, 2001), todavia, percebemos que algumas zonas aparecem de forma mais expressiva do que outras. A zona animista foi a menos utilizada, isto é, a ideia de calor como substancia capaz de dar vida a meios e objetos, apareceu em poucos momentos. Sendo assim, constatamos que os docentes não atribuem vida ao conceito de calor.

Assim, em alguns momentos das aulas os professores não conseguiram utilizar da diversidade de contextos, isto é, durante a explanação das aulas, não foram explorados exemplos que permitissem a empregabilidade de forma expressiva dos diversos significados que abrange o conceito de calor, mas isso pode ser justificado por conta de algumas possíveis limitações da formação. De acordo com Diniz et al, (2015), essas limitações da formação ocorrem, pois é necessário estabelecermos uma formação epistemológico do docente a partir da teoria dos perfis conceituais, para que assim possamos formar educadores que entendam o discurso heterogêneo da sala de aula e aprendam a incorporar no processo de ensino e aprendizagem diferentes formas de trabalhar os conceitos científicos e cotidianos a partir de diferentes modos de pensar e formas de falar.

\section{Considerações Finais}

A partir deste estudo, analisamos modos de pensar o conceito de calor mobilizado na fala de dois Professores de Ciências do $9^{\circ}$ ano do Ensino Fundamental atuantes na rede pública da cidade de São Raimundo Nonato no estado do Piauí. E por meio deste estudo, ao analisar dados do questionário, da observação e filmagens das três aulas de Ciências sobre o 
conteúdo Calor, foi possível identificar a heterogeneidade presente no discurso dos docentes participantes da pesquisa, no qual expressam os diferentes modos de pensar e falar Calor alinhados a visão científica e não-científica.

Assim, diante dos resultados alcançados, consideramos que foi possível identificar o perfil profissional, bem como os modos de pensar o conceito de calor na fala dos professores participantes. Assim, identificarmos na fala deles a presença das cinco zonas do perfil conceitual de calor: racionalista, empírica, substancialista, realista e animista, ressalvamos que as zonas racionalista, empírica e substancializa emergiram de forma mais expressiva.

O que demostrou a estreita relação entre a formação de cada docente com os conhecimentos que eles utilizam em sala de aula, e tal fato aponta a necessidade de uma melhor formação dos professores para trabalharem conteúdos mais específicos no $9^{\circ}$ ano do Ensino Fundamental, uma vez que a limitação da formação faz com que seu discurso em sala de aula fique limitado as ideias dos livros didáticos, bem como as ideias mais ingênuas do conceito, e isso pode acarretar em problemas no processo de conceituação dos estudantes.

Por isso, destacamos a necessidade dos professores no contexto da sala de aula tentar explorar mais os variados contextos que o conceito de calor se insere, mas que compreenda os diferentes modos de pensar e formas de falar, bem como entendam a importância do contexto científico escolar na aprendizagem conceitual dos seus estudantes.

Assim sendo, defendemos que os professores se conscientizem acerca da heterogeneidade dos conceitos, e reconheçam que eles têm um papel importante no processo de construção de significados e que podem ajudar os estudantes a compreenderem que os conhecimentos cotidiano e científico podem caminhar juntos, ampliando assim o universo do processo de ensinar e aprender Ciências, conforme defendido pela teoria dos perfis conceituais.

Ressalvamos, que a partir das discussões aqui apresentadas, pretendemos dar continuidade à nossa pesquisa envolvendo o uso dos perfis conceituais na compreensão, planejamento e contextualização do ensino de ciências.

\section{Referências}

Amaral, E. M. R., \& Mortimer, E. F. (2001). Uma proposta de perfil conceitual para o conceito de calor. Revista Brasileira de Pesquisa em Educação em Ciências. 1, 1-16. https://periodicos.ufmg.br/index.php/rbpec/article/view/4154

Amaral, E. M. R., \& Mortimer, E. F. (2005). Proposta metodológica para análise da dinâmica discursiva em sala de aula. Associação brasileira de pesquisa em educação em ciências. Atas do VENPEC - n. 5. http://abrapecnet.org.br/atas_enpec/venpec/conteudo/artigos/3/pdf/p772.pdf

Amaral, E. M. R., \& Mortimer, E. F. (2006). Uma metodologia para análise da dinâmica entre zonas de um perfil conceitual no discurso da sala de aula. A pesquisa em ensino de ciências no Brasil e suas metodologias. Ed. Unijuí. 239-296.

Amaral, E. M. R., Ratis, S. J. R., \& Sabino, J. (2018). Analysing processes of conceptualization for students in lessons on substance from the emergence of conceptual profile zones. Chemistry Education Research and Practice iosi, 3, 1-19. https://www.researchgate.net/figure/Activities-carried-out-in-theTLS_tbl1_324994974

Araújo, A. O. (2014). O Perfil Conceitual de Calor e sua Utilização por Comunidades Situadas. 223 f. Tese (doutorado em educação e ciências) - Programa de Pós-graduação em Educação, Universidade Federal de Minas Gerais, Belo Horizonte, Minas Gerais, Brasil. https://repositorio.ufmg.br/bitstream/1843/BUOS-9JHKBE/1/tese_ang_lica_ara_jo.pdf

Araújo, A. O., \& Mortimer, E. F. (2014). Estudo preliminar sobre a utilização do perfil conceitual de calor em curso para manutenção e instalação de aparelhos de refrigeração. In: XVI Encontro Nacional de Ensino de Química/ X Encontro de Educação Química da Bahia/BA 2014.

Castro, P. M. A., \& Ferreira, L. N. A. (2015). Representações sociais de calor por estudantes de graduação em química. Química nova escola. 37, 26-34. http://qnesc.sbq.org.br/online/qnesc37_especial_I/06-AF-98-14.pdf

Capecchi, M. C. V., \& Carvalho, A. M. P. (2000). Argumentação em uma aula de conhecimento físico com crianças na faixa de oito a dez anos. Investigações em Ensino de Ciências. 5(3), 171-189. https://www.if.ufrgs.br/cref/ojs/index.php/ienci/article/view/592

Coutinho, F. A., \& Mortimer, E. F.; El-Hani, C. N. (2007). Construção de um Perfil para o conceito biológico de vida. Investigações em Ensino de Ciências. 12(1), 115-137. https://www.if.ufrgs.br/cref/ojs/index.php/ienci/article/view/480

Diniz Jr., Silva, J. R. R. T., \& Amaral, E. M. R. (2015). Zonas do Perfil Conceitual de Calor que Emergem na Fala de Professores de Química, Química nova Escola. 37, 55-67.2015. http://qnesc.sbq.org.br/online/qnesc37_especial_I/09-CP-99-14.pdf

Diniz Jr., A. I. \& Amaral, E. M. R. (2019). A Heterogeneidade do Discurso Docente: falando sobre substâncias a partir de diferentes situações. Revista Debates em Ensino de Química, 5,42-54. http://www.journals.ufrpe.br/index.php/REDEQUIM/article/view/2438/482483192 
Research, Society and Development, v. 10, n. 10, e499101018930, 2021

(CC BY 4.0) | ISSN 2525-3409 | DOI: http://dx.doi.org/10.33448/rsd-v10i10.18930

El-Hani. C. N., Mortimer, E. F., \& Silva. F. (2013). As bases epistemológicas da teoria dos perfis conceituais. In: IX Encontro Nacional de Pesquisa em Educação em Ciências - IX ENPEC, Águas de Lindóia, SP. http://abrapecnet.org.br/atas_enpec/ixenpec/atas/resumos/R0941-1.pdf

Freire, M. S., Talanquer, V. A., \& Amaral, E. M. R. (2019) Conceptual profile of chemistry: a framework for enriching thinking and action in chemistry education. International Journal of Science Education, 41, 674-692. https://repository.arizona.edu/bitstream/handle/10150/631979/Freire_IJSE_2019.pdf

Guerra, E. L. A. (2014). Manual Pesquisa Qualitativa. Anima Educação.

Mortimer, E. F. (1995). Conceptual Change or Conceptual Profile Change? Science \& Education. Netherlands: Kluwer Academic Publishers, 268-283.

Mortimer, E. F., \& Amaral, L. O. F. (1998). Quanto mais quente melhor, calor e temperatura no ensino de termoquímica. Química Nova Escola. 7, 30. http://qnesc.sbq.org.br/online/qnesc07/aluno.pdf

Mortimer, E. F., \& El-Hani, C. N. (2014). Conceptual Profiles: A Theory of Teaching and Learning Scientific Concepts. Springer.

Sabino, J. D., \& Amaral, E. M. R. (2018). Utilização do perfil conceitual de substância no planejamento do ensino e na análise do processo de aprendizagem. Investigações em Ensino de Ciências, 23, 245-265. https://www.if.ufrgs.br/cref/ojs/index.php/ienci/article/view/923

Santos, R. P., \& Carbó, A. D. (2014). Uma Proposta De Perfil Conceitual Para O Conceito De Massa. In IX Encontro Nacional De Pesquisa Em Ensino De Física. Jaboticatubas/MG: SBF.

Schnetzler, R. P. (1992). Construção do conhecimento e ensino de ciências. Em Aberto, Brasília, ano 11, nº 55, jul./set. 1992.

Silva, J. R. R. T., \& Amaral, E. M. R. (2013). Proposta de um Perfil Conceitual para Substância. Revista Brasileira de Pesquisa em Educação em Ciências, 13. 53-72. https://periodicos.ufmg.br/index.php/rbpec/article/view/4271/2836

Simões Neto, J. E. (2016). Uma Proposta para o Perfil Conceitual de Energia em Contextos do Ensino da Física e da Química. Tese (Doutorado em ensino de Ciências). Departamento de Educação, Universidade Federal Rural de Pernambuco, Recife, Pernambuco, Brasil. http://www.ppgec.ufrpe.br/sites/www.ppgec.ufrpe.br/files/documentos/uma_proposta_para_o_perfil_conceitual_de_energia_em_contextos_do_ensino_da_fisi ca_e_da_quimica.pdf 